\title{
THIN-LAYER CHROMATOGRAPHY ON REVERSED PHASE IN THE CHARACTERIZATION OF RETENTION BEHAVIOUR, LIPOPHILICITY, AND PHARMACOKINETICS OF CYANOACETAMIDE DERIVATIVES
}

\author{
SUZANA APOSTOLOV ${ }^{{ }^{*}}$, GYÖNGYI VASTAG ${ }^{1}$, BORKO MATIJEVIĆ ${ }^{1}$, TATJANA ĐAKOVIĆ-SEKULIĆ ${ }^{1}$ AND \\ ALEKSANDAR MARINKOVIĆ ${ }^{2}$
}

\author{
${ }^{1}$ University of Novi Sad, Faculty of Sciences, Department of Chemistry, Biochemistry and Environmental Protection, Trg Dositeja Obradovića 3, 21000 Novi Sad, \\ Serbia. \\ ${ }^{2}$ University of Belgrade, Faculty of Technology and Metallurgy, Karnegijeva 4, 11000 Belgrade, Serbia.
}

\begin{abstract}
Biological activity of a molecule is closely related to its lipophilicity. This significant parameter was determined for a group of potentially bioactive $\mathrm{N}$-(4-phenylmonosubstituted)-2-cyanoacetamides applying thin-layer chromatography on reversed phase (RP-TLC) in mixtures of water and two organic modifiers separately, $i$-propanol and dioxane. The effect of the chemical structure of derivatives and the influence of the applied organic modifier on their retention were studied. The determined chromatographic retention constants, $R_{\mathrm{M}}{ }^{0}$, and the chromatographic parameter, $m$, of compounds were correlated with software calculated partition coefficients, $\log P$ as the standard measure of lipophilicity and with different pharmacokinetic predictors applying classical linear and multiple regression analysis. By classical linear regression analysis in both water-modifier systems only $R_{\mathrm{M}}{ }^{0}-\log P$ and $m$ - $\log P$ correlations were established (average $\mathrm{r}, 0.909$ and 0.826 ). All studied relationships were enhanced by molecular descriptors that fulfilled the modified Lipinski's rule of five. Thereby, the performed multiple regression analysis gave better correlations (for $R_{\mathrm{M}}{ }^{0} \log P$ and $m-\log P$ average $\mathrm{r}^{2}, 0.994$ and 0.993 ; for $R_{\mathrm{M}}{ }^{0}$-pharmacokinetic parameters and $m$-pharmacokinetic parameters average $\mathrm{r}^{2} 0.978$ and 0.980$)$. The obtained results indicate that the chromatographic parameters, $R_{\mathrm{M}}{ }^{0}$ and $m$ determined by RP-TLC at given conditions could be used successfully for the description of lipophilicity and the evaluation of pharmacokinetic properties of $N$-(4-phenylmonosubstituted)-2-cyanoacetamides as potential bioactive molecules.
\end{abstract}

Keywords: $N$-(4-phenylmonosubstituted)-2-cyanoacetamides, RP-TLC, lipophilicity, Lipinski's molecular descriptors, pharmacokinetic predictors .

\section{INTRODUCTION}

A large number of modern scientific research is based on the targeted synthesis of compounds with promising biological activity. Since it is easier to perform the synthesis of molecules with a definite chemical structure than with certain properties, the greatest attention of contemporary scientists is focused on the important steps which precede the synthesis of new molecules. According to the investigation in 2010 an average investment of pharmaceutical companies in discovering and bringing the new molecule entity to market costs approximately 1.8 billion dollars. ${ }^{1}$ For that reason, the detection of pharmacophore, modelling the preferred characteristics of the new compounds (adequate absorption, distribution, metabolism, excretion and toxicity), especially predicting their behaviour in an organism are the key steps in drug discovery.

In many new derivatives that have been synthesized in the last 15 years, the amide group is the most frequent functional group responsible for some type of physiological response..$^{2-6}$ The acetamides are singled out from the rest of the derivatives of amides by the diversity of their pharmacological properties. It has been found that some derivatives of acetamides are used as antiprotozoics 7,8 , as bactericides ${ }^{9}$, in agriculture as insecticides ${ }^{10}$, herbicides ${ }^{11}$ and fungicides ${ }^{12}$ It is not unknown that many of them are applied as analgesics ${ }^{13}$, anticonvulsants ${ }^{14}$ and antioxidants. ${ }^{15}$ Also, recent research has indicated that some acetamides could successfully be applied as melatonin analogs ${ }^{16}$, lidocaine analogs ${ }^{17}$, positive allosteric modulators of sigma-1 receptor ${ }^{18}$ and potential acetylholinesterase inhibitors. ${ }^{19}$ Besides all the above mentioned application, the pharmacological tests are mostly directed to the discovery of derivatives with antitumor activity ${ }^{20,21}$ and HIV inhibitory properties. ${ }^{22}$

The recognition of bioactive substances is closely related to the knowledge about the relationship between the structure, the physicochemical characteristics, and the potential activities that the new molecule may exhibit in the biological medium. It is undeniable that the nature of the substituent linked to the basic molecule causes type and intensity of activity of compounds. ${ }^{23}$ Also, the fact that the properties of some substances highly depend on the medium in which they are located, and the interactions that they achieved at the site of action, must not be ignored. ${ }^{24}$ In accordance with that, rational design of drug at an early phase would primarily include the quantification of the effect of structural changes on the relevant feature of the new biologically active molecules.
For that purpose, models of Quantitative Structure-Activity Relationship (QSAR) and Quantitative Structure-Property Relationship (QSPR) are most frequently used..$^{25,26}$

The number of excessive parameters is reduced and thus a reliable selection of those parameters that are essential for adequate biological activity of the observed molecules can be performed. In QSAR and QSPR studies, among the numerous molecular descriptors, lipophilicity plays a central role as the most important physicochemical parameter of molecule which significantly influences its bioactivity. ${ }^{27-29}$

Lipophilicity largely determines the transport of components through the cell membrane affecting the formation of complexes of the tested substances with plasma proteins or with the (in) appropriate receptor at the site of action..$^{30}$ Therefore, the evaluation of the lipophilic character of compounds is an essential step in contemporary drug design. The lipophilicity of molecules can be determined and expressed in different ways. Commonly it is expressed as a $\operatorname{logarithm}$ of its partition coefficient, $\log P$ (the logarithm of the ratio of the concentrations of solute in a saturated 1-octanol-water system). ${ }^{31,32}$ Also, for getting information about lipophilicity and bioproperties of molecules in Quantitative Structure-Retention Relationship (QSRR) model, the values of chromatographic retention parameter, $R_{\mathrm{M}}{ }^{0}$, obtained by RP-TLC are widely used. ${ }^{33-37}$ Thin layer chromatography on reversed phase has proved to be a suitable method between various chromatographic methods, thanks to its simplicity, price, using small amounts of the substance, accuracy, repeatability and efficiency, as well as the possibility of differentiating of lipophilicity between structurally similar molecules. ${ }^{38}$

The evaluation of a molecule as a potential therapeutic agent may be further improved by introducing the Lipinski's rule of five. ${ }^{39}$ This rule includes a set of molecular descriptors that may be used to predict whether a molecule exhibits adequate absorption and permeability i.e. satisfactory bioavailability. The rule states that orally biologically active compound (potential therapeutic) should own: $\log P<5$, molecular weight $<500$, number of hydrogen bond acceptors $<$ $10(2 \cdot 5)$ and number of hydrogen bond donors $<5$. Besides these, for the same purpose several other molecular descriptors like molar refractivity, molecular volume could often applied. 
Also, the early stages of design of bioactive compounds include the study of the pharmacokinetic and pharmacodynamic characteristics that determine the bioavailability as one of the most important features of the future therapeutic agents. Absorption, distribution, metabolism, elimination and toxicity (ADMETox properties) of a compound are crucial for assessing the effectiveness of future drug in biological medium. The knowledge of important pharmacokinetic characteristics that largely determine bioavailability contributes to the optimization of chemical synthesis of the target molecule as well as its biological activity, with substantial saving money and acceleration of the development of a potential drug.

If a bioactive substance (drug) is administered intravenously its bioavailability is complete. Due to its simplicity, oral administration is the most common administration of the drug, but also causes prolongation of the development time of the future bioactive compound. ${ }^{40}$ The primary determinant of a substance's good bioavailability is intestinal absorption. ${ }^{41,42}$ One of the key pharmacokinetic parameter which enables prediction the rate and extent of intestinal absorption is the human effective permeability in jejunum $\left(P_{\text {eff }}\right){ }^{43}$ Biologically active compounds from the intestinal lumen are usually subjected to the passive transcelullar transport i.e. diffusion through the phospholipid bilayer of enterocytes. Hence, molecules with higher lipophilicity have better permeability, respectively higher values of $P_{\text {eff }}$ and thus they easier pass from the intestinal lumen into the blood. ${ }^{44}$ The pharmacokinetic parameter that allows the prediction of the distribution of bioactive molecules in the circulatory system is blood to plasma concentration ratio, $R P B$. Namely, if the $R P B>1$, the high concentration of the molecule is in the blood, and there is a risk of its accumulation in the erythrocytes, wherein it can be considered hematotoxic. ${ }^{45}$ Compounds that are less bounded to the plasma proteins penetrate the tissue more efficiently than those that are highly bound. ${ }^{46}$ If the substance is reversibly bound to the plasma proteins, there is a balance between bound and unbound forms. The unbound fraction is the one that exhibits the pharmacological effect, and the bound fraction could behave as a depot from which the agents are slowly released as the unbound form when the unbound form is being metabolized and/or excreted from the body. For the interpretation of activities and effectiveness of the component, its half-life and potential side effects, it is important to have information about the unbound fraction, Unbnd. ${ }^{47}$ Closely related to this pharmacokinetic parameter is the volume of distribution, $V d$, which represent the proportionality factor that relates the total amount of the drug in the body to the concentration of drug measured in the plasma. ${ }^{48} \mathrm{High}$ value of $V d$, this suggests that the compound is lipophilic and it is distributed widely to the tissues, especially into fat tissue. ${ }^{49}$ The blood-brain barrier (BBB) represents a highly selective mechanism that controls the passage of substances from the blood to the brain extracellular fluid in the central nervous system (CNS). The brain tissue is unavailable to a large number of active substances due to their large size or small lipophilicity. Literature data indicates that compounds with pharmacokinetic parameter log $B B B>0.3$ have good predispositions as neurologically active substances, while $\log B B B<-1$ indicates a blocking of the passage through the blood brain barrier. ${ }^{50}$

One of the aims of this paper was the study of the chromatographic behaviour of newly synthesized $\mathrm{N}$-(4-phenylmonosubstituted)-2-cyanoacetamides by applying RP-TLC. The quantitative dependence between the experimental and mathematical parameters of lipophilicity was examined as well as the correlation of experimental parameters of lipophilicity and important pharmacokinetic parameters. These correlations were performed by classical linear regression method. The obtained relationships were more precisely defined by applying multiple regression analysis after introducing descriptors which fulfilled the modificated Lipinski's rule of five.

\section{EXPERIMENTAL}

The examined cyanoacetamide derivatives are presented in Table 1. Their synthesis has been previously published in the literature ${ }^{51}$ The tested compounds were dissolved in ethanol $\left(2 \mathrm{mg} \mathrm{mL}^{-1}\right)$ and freshly prepared solutions $(0.2 \mathrm{ml})$ were spotted on the stationary phase (RP-TLC C18/UV254 plates, MachereyNagel GmbH and Co., Düren, Germany). The plates were developed in normal unsaturated chambers at room temperature by ascending technique with aqueous solutions of two organic modifiers: $i$-propanol $(\varphi=0.34-0.52, \mathrm{v} / \mathrm{v})$ and dioxane $(\varphi=0.32-0.50, \mathrm{v} / \mathrm{v})$. Organic modifiers used for preparing the chromatographic solutions and for performing of development were LC grade (J.T. Baker, Deventer, The Netherlands). After development, chromatograms were dried at room temperature.
The identification of the developed compounds was performed by using UV light, $\lambda=254 \mathrm{~nm}$, wherein on the fluorescence basis dark spots occurred. In both applied modifiers for each compound at least three chromatograms were developed and then the average $R_{\mathrm{f}}$ values were calculated.

Table 1. Structures of the investigated $N$-(4-phenylmonosubstituted)-2cyanoacetamides.

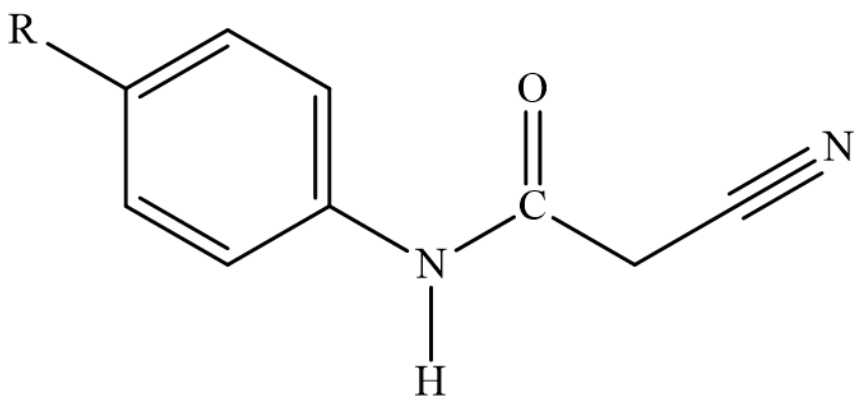

\begin{tabular}{|c|c|}
\hline compound & R \\
\hline 1. & $\mathrm{H}$ \\
\hline 2. & $\mathrm{CH}_{3}$ \\
\hline 3. & $\mathrm{I}$ \\
\hline 4. & $\mathrm{Br}$ \\
\hline 5. & $\mathrm{NO}_{2}$ \\
\hline 6. & $\mathrm{OH}$ \\
\hline 7. & $\mathrm{COOH}$ \\
\hline 8. & $\mathrm{COCH}_{3}$ \\
\hline 9. & $\mathrm{C}_{2} \mathrm{H}_{5}$ \\
\hline
\end{tabular}

The obtained experimental data was processed by a software package Origin, version 6.1. Standard lipophilicity values, $\log P$, were calculated using virtual Computational Chemistry Laboratory, $V C C L A B^{52}$ descriptors that fulfilled the Lipinski's rule of five were calculated by the online program Molinspiration ${ }^{53}$ and values of pharmacokinetic parameters, $P_{e f f}, R P B, U n b n d, V d$ and $\log B B B$, for the tested compounds were calculated using the online program SimulationPlus. ${ }^{54}$

\section{RESULTS AND DISCUSSION}

\section{Retention behaviour of $N$-(4-phenylmonosubstituted)-2-cyanoacetamides}

The biological activity of a compound significantly depends on the type and intensity of the interaction which it can achieve with its surroundings. These interactions are very similar to those that substances can establish with mobile and stationary phase during chromatographic analysis. In order to examine the retention properties and evaluate lipophilicity (potential biological activity) of newly synthesized $N$-(4-phenylmonosubstituted)-2-cyanoacetamides RP-TLC was performed in one protic solvent ( $i$-propanol) and one aprotic solvent (dioxane). The chromatographic retention behaviour of the tested cyanoacetamides is presented in Table 2 .

Table 2. $R_{\mathrm{f}}$ values of studied cyanoacetamides (RP-C18 TLC stationary phase, applied mobile phases contain $60 \%$ water and $40 \%$ organic modifier).

\begin{tabular}{|c|c|c|c|}
\hline \multirow{2}{*}{ compound } & \multicolumn{3}{|c|}{ modifier } \\
\cline { 2 - 4 } & $\boldsymbol{i}$-propanol & dioxane \\
\cline { 2 - 4 } & & $\boldsymbol{R}_{\mathbf{f}}$ & \\
\hline 1. & 0.632 & & 0.576 \\
\hline 2. & 0.534 & & 0.480 \\
\hline 3. & 0.385 & & 0.294 \\
\hline 4. & 0.429 & & 0.359 \\
\hline 5. & 0.522 & & 0.455 \\
\hline 6. & 0.804 & & 0.771 \\
\hline 7. & 0.829 & & 0.826 \\
\hline 8. & 0.672 & & 0.610 \\
\hline 9. & 0.465 & & 0.339 \\
\hline
\end{tabular}

$\mathrm{T}$ |he values of the retention parameters (Table 2) show that the retention behaviour of the examined cyanoacetamides is influenced by the applied organic solvent as well as the nature of the substituent $-\mathrm{R}$ in the molecule. 
$R_{\mathrm{f}}$ values obtained for the same compound in applied organic modifiers show that slightly higher retention was registered in aprotic dioxane. This is probably caused by the fact that dioxane is non-polar solvent, unlike $i$-propanol, so it can establish stronger hydrophobic interactions with phenyl group of the solute.

The data presented in Table 2 also indicate that the nature of the substituent $\mathrm{R}$ at the 4 position on the benzene ring has greater impact on the retention of the examined compounds, than the applied organic modifier. This has already been confirmed in the literature.$^{55}$ As expected, increasing the polarity of substituent $\mathrm{R}$ leads to shorter retention of the tested derivatives in a less polar stationary phase. Consequently the $R_{\mathrm{f}}$ values of the compounds with polar substituents increase in the following order $\left(-\mathrm{COOH}>-\mathrm{OH}>-\mathrm{COCH}_{3}\right)$ compared to the unsubstituted molecule $(-\mathrm{H})$ in both applied modifiers. The deviation is noticeable only in the case of derivative 5 , which has $-\mathrm{NO}_{2}$ group as a substituent. Even though it is polar, the presence of $-\mathrm{NO}_{2}$ group in compound 5 leads to the increasing of lipophilicity compared to the unsubstituted molecule. The reason for this is probably the existence of mesomeric structures, which may lead to an increase in the partial charge on the amide nitrogen atom. ${ }^{56}$ In both used modifiers, the weakest retention is registered for compound 7 with - $\mathrm{COOH}$ group as substituent. Such retention behaviour of compound 7 is the result of the largest polarity of $-\mathrm{COOH}$ group among all of the studied substituents, as well as its negative inductive and resonance effect. The opposite phenomenon is noticed in the presence of non-polar group in the molecule. The increase of a non-polar character of alkyl substituent $\left(-\mathrm{CH}_{3}<-\mathrm{C}_{2} \mathrm{H}_{5}\right)$ results in the stronger retention in relation to the basic molecule $(-\mathrm{H})$. Similarly, halogen substituents increase the hydrophobicity of the molecule, and therefore retention: $-\mathrm{Br}<-\mathrm{I}$. The phenomenon can be interpreted as the result of the difference of London's dispersion interaction between the halogen atoms and the non-polar stationary phase ${ }^{57}$ The strongest retention in both used modifiers is measured for compound 3 , with $-\mathrm{I}$ as a substituent.

Experimental determination of the lipophilicity of $\mathrm{N}-(4-$ phenylmonosubstituted)-2-cyanoacetamides

A more detailed insight into the effect of mobile phase on the chromatographic retention behaviour of $N$-(4-phenylmonosubstituted)-2-cyanoacetamides can be obtained by varying the amount of organic modifier, $\varphi$, in the mobile phase.

From the experimentally obtained $R_{\mathrm{f}}$ values the retardation factor, $R_{\mathrm{M}}$, was calculated:

$$
R_{\mathrm{M}}=\log \left(1 / R_{\mathrm{f}}-1\right)
$$

The calculated $R_{\mathrm{M}}$ values were extrapolated to zero concentration of organic modifier:

$$
R_{\mathrm{M}}=R_{\mathrm{M}}{ }^{0}+m \varphi
$$

where $\varphi$ is the volume fractions of the organic solvent in the mobile phase, intercept, $R_{\mathrm{M}}{ }^{0}$, represents the chromatographic retention constant, which is often used as a measure of the lipophilicity of the compound, while the slope of linear plot, $m$, corresponds to the chromatographic parameter, which largely depends on the properties of the solute and also can be applied as alternative measure of lipophilicity. ${ }^{58,59}$ Values of these parameters obtained in $i$-propanol and dioxane as modifiers are shown in Table 3 . The validity of the linear dependence between the retention parameter, $R_{\mathrm{M}}$, and the volume fraction of the organic solvent, $\varphi$, in the chosen field of experimental work for all tested organic modifiers is confirmed with by the high values of the regression coefficients, $r$.

\begin{tabular}{|c|c|c|c|c|c|c|c|c|}
\hline \multirow{2}{*}{ substituent } & \multicolumn{4}{|c|}{$i$-propanol } & \multicolumn{4}{|c|}{ dioxane } \\
\hline & $\boldsymbol{R}_{\mathrm{M}}{ }^{0}$ & $m$ & $\mathbf{r}$ & sd & $R_{\mathrm{M}^{0}}$ & $m$ & $\mathbf{r}$ & sd \\
\hline $\mathrm{H}$ & 0.680 & -2.202 & -0.984 & 0.029 & 0.454 & -1.520 & 0.993 & 0.017 \\
\hline $\mathrm{CH}_{3}$ & 1.188 & -3.122 & -0.991 & 0.035 & 0.985 & -2.494 & 0.966 & 0.054 \\
\hline I & 1.942 & -4.331 & -0.997 & 0.029 & 1.631 & -3.235 & 0.992 & 0.033 \\
\hline $\mathrm{Br}$ & 1.791 & -4.159 & -0.996 & 0.032 & 1.382 & -2.888 & 0.991 & 0.032 \\
\hline $\mathrm{NO}_{2}$ & 1.263 & -3.243 & -0.997 & 0.205 & 0.990 & -2.330 & 0.980 & 0.038 \\
\hline $\mathrm{OH}$ & 0.128 & -1.915 & -0.982 & 0.027 & 0.272 & -1.920 & 0.989 & 0.026 \\
\hline $\mathrm{COOH}$ & 0.769 & -3.186 & -0.984 & 0.048 & -0.039 & -1.618 & 0.969 & 0.038 \\
\hline $\mathrm{COCH}_{3}$ & 0.813 & -2.888 & -0.994 & 0.022 & 0.739 & -2.423 & 0.990 & 0.028 \\
\hline $\mathrm{C}_{2} \mathrm{H}_{5}$ & 1.821 & -4.332 & -0.992 & 0.039 & 1.250 & -2.445 & -0.991 & 0.021 \\
\hline
\end{tabular}

Table 3. The parameters of chromatographic equations obtained for cyanoacetamides in the applied solvents.

From data presented in Table 3 it can be noticed that the values of the intercept, $R_{\mathrm{M}}{ }^{0}$, follow the values of slope, $m$, for all the examined cyanoacetamides in the applied modifiers. This can be explained by the fact that both chromatographic constants depends on the same physico-chemical parameters. ${ }^{60}$ In order to confirm this phenomenon, chromatographic parameters, $R_{\mathrm{M}}{ }^{0}$ and, $m$, were correlated (Table 4 ).

Table 4. Equations of relationship between intercept, $R_{\mathrm{M}}{ }^{0}$, and slope, $m$ in applied modifiers.

\begin{tabular}{|l|l|l|l|}
\hline modifier & equation & r & sd \\
\hline$i$-propanol & $R_{\mathrm{M}}{ }^{0}=-1.038-0.672 m$ & 0.961 & 0.182 \\
\hline dioxane & $R_{\mathrm{M}}^{0}=-1.230-0.898 m$ & 0.921 & 0.228 \\
\hline
\end{tabular}

The high values of correlation coefficient indicate the validity of the established linear dependences for examined cyanoacetamides.

Mathematical determination of the lipophilicity of $\mathrm{N}-(4-$ phenylmonosubstituted)-2-cyanoacetamides

In this paper, the lipophilicity of the newly synthesized cyanoacetamides as an indicator of their potential biological activity was also determined computationally. Applying different mathematical methods developed under the software package VCCLAB 2007 for the investigated cyanoacetamides were calculated values of standard measure of lipophilicity, $\log P$ (Table 5).
Table 5. Computational calculated $\log P$ values of studied cyanoacetamides.

\begin{tabular}{|c|c|c|c|c|c|c|c|}
\hline comp. & AClog $\boldsymbol{P}$ & Alog $\boldsymbol{P}$ & ABlog $\boldsymbol{P}$ & Mlog $\boldsymbol{P}$ & milog $\boldsymbol{P}$ & kowwin & Xlog $\boldsymbol{P}_{3}$ \\
\hline $\mathrm{H}$ & 1.60 & 1.01 & 0.89 & 1.02 & 0.57 & 1.35 & 1.58 \\
\hline $\mathrm{CH}_{3}$ & 1.92 & 1.50 & 1.3 & 1.33 & 1.02 & 1.90 & 2.14 \\
\hline $\mathrm{I}$ & 2.53 & 1.59 & 2.34 & 1.89 & 1.66 & 2.52 & 3.15 \\
\hline $\mathrm{Br}$ & 2.30 & 1.76 & 1.87 & 1.74 & 1.38 & 2.24 & 2.73 \\
\hline $\mathrm{NO}_{2}$ & 1.47 & 0.90 & 1.14 & 1.02 & 0.53 & 1.89 & 2.10 \\
\hline $\mathrm{OH}$ & 1.30 & 0.74 & 0.08 & 0.48 & 0.09 & 0.52 & 0.95 \\
\hline $\mathrm{COOH}^{-1.12}$ & 0.61 & 0.85 & 0.73 & 0.48 & 1.23 & 1.75 \\
\hline $\mathrm{COCH}_{3}$ & 1.52 & 0.75 & 0.93 & 1.00 & 0.47 & 1.03 & 1.68 \\
\hline $\mathrm{C}_{2} \mathrm{H}_{5}$ & 2.28 & 1.95 & 1.78 & 1.62 & 1.49 & 2.39 & 2.62 \\
\hline
\end{tabular}


It is apparent from the data in Table 5 that for the same compound different values of partition coefficient, $\log P$, were obtained which is a consequence of the different mathematical methods applied for calculating this parameter. The highest value of partition coefficient was calculated for compound 3 and the lowest value was calculated for compound 7, which is in accordance with the obtained chromatographic data.

The correlation between experimentally and mathematically obtained lipophilicity of $N$-(4-phenylmonosubstituted)-2-cyanoacetamides

Given that the chromatographic retention constant, $R_{\mathrm{M}}{ }^{0}$, represents the total effect of the intermolecular interactions of the solute with a stationary and a mobile phase, it is clear that it can be applied as a measure of lipophilicity. In order to confirm this fact in the case of the investigated derivatives of $\mathrm{N}$-(4substituted phenyl)-2-cyanoacetamide, their experimentally determined lipophilicity, $R_{\mathrm{M}}{ }^{0}$, and alternative measure of lipophilicity, $m$, are correlated with the software calculated partition coefficient, $\log P$, as a standard measure of lipophilicity applying method of linear regression. Figure 1 and Figure 2 show obtained dependences $\mathrm{X} \log P_{3}-R_{\mathrm{M}}{ }^{0}$ and $\mathrm{X} \log P_{3}-m$ in $i$-propanol as a modifier, respectively.

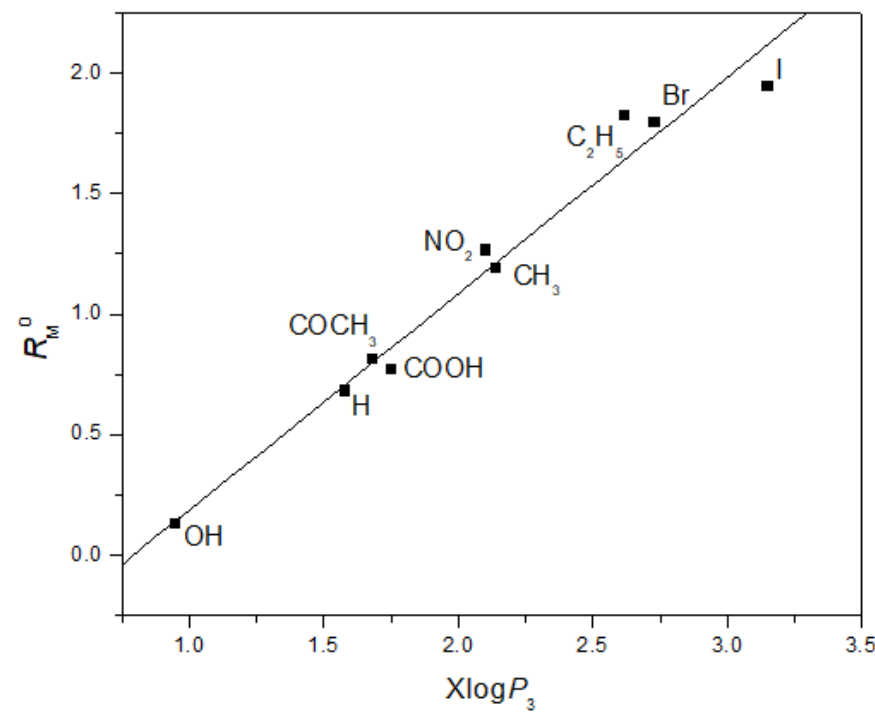

Figure 1. Dependence of $R_{\mathrm{M}}^{0}$ values obtained in $i$-propanol on Xlog $P_{3}$.

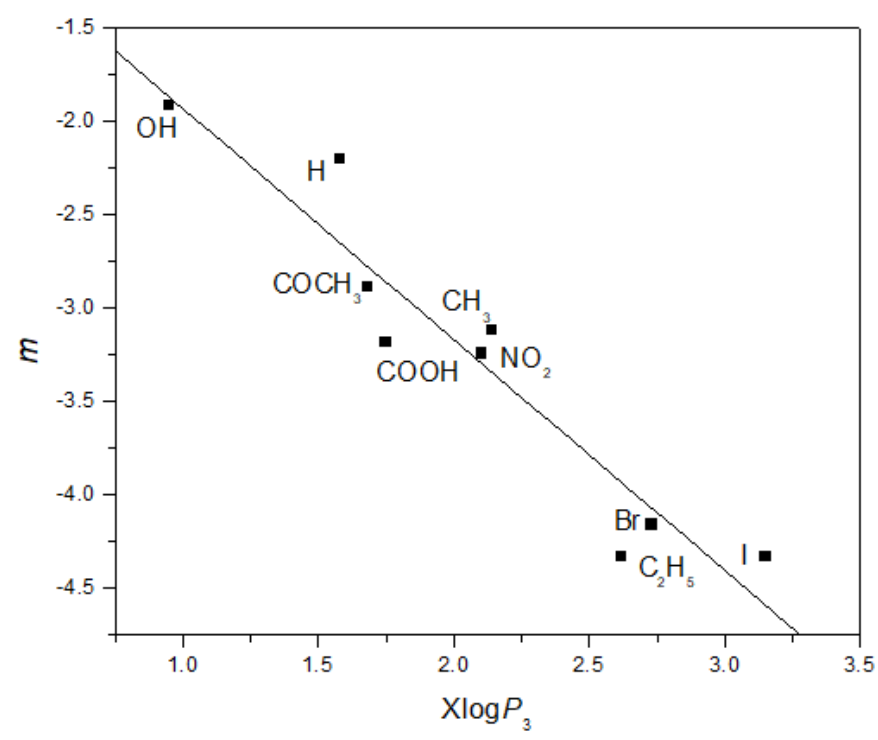

Figure 2. Dependence of $m$ values obtained in $i$-propanol on $\mathrm{X} \log P_{3}$.

From Figure 1 and Figure 2 the existence of linear dependence of experimentally and computationally obtained lipophilicity for the tested derivatives in $i$-propanol can be noticed. In Table 6 , the correlation matrix obtained as a result of the linear regression analysis between chromatographic parameters of the examined compounds, $R_{\mathrm{M}}{ }^{0}$ and $m$, determined in both used modifiers and various $\log P$ values, is shown.

Table 6. Correlation matrix obtained between various $\log P$ values and chromatographic retention parameters $R_{\mathrm{M}}{ }^{0}$ and $m$, of tested cyanoacetamides.

\begin{tabular}{|c|c|c|c|c|c|c|c|}
\hline modifier & AClog $\boldsymbol{P}$ & Alog $\boldsymbol{P}$ & $\mathbf{A B l o g} \boldsymbol{P}$ & milog $\boldsymbol{P}$ & Mlog $\boldsymbol{P}$ & kowwin & Xlog $\boldsymbol{P}_{3}$ \\
\hline$R_{\mathrm{M}}{ }^{0}(i$-propanol $)$ & 0.881 & 0.846 & 0.975 & 0.946 & 0.952 & 0.976 & 0.986 \\
\hline$m(i$-propanol $)$ & 0.795 & 0.771 & 0.926 & 0.904 & 0.875 & 0.902 & 0.950 \\
\hline$R_{\mathrm{M}}{ }^{0}$ (dioxane) & 0.925 & 0.831 & 0.882 & 0.863 & 0.922 & 0.866 & 0.879 \\
\hline$m($ dioxane $)$ & 0.828 & 0.678 & 0.804 & 0.771 & 0.824 & 0.720 & 0.815 \\
\hline
\end{tabular}

From Table 6 it is evident that better relationships of all the calculated partition coefficients are achieved with the retention constants, $R_{\mathrm{M}}{ }^{0}$, determined in $i$ propanol. On the other hand, among all the computed values of partition coefficient, Xlog $P_{3}$ shows the best correlation with chromatographic constants obtained in $i$-propanol and partition coefficient, AClog $P$ showed the best agreement with the chromatographic parameters determined in dioxane.

However, these relationships were not satisfactory in the case of all the tested derivatives. Since the values of partition coefficients $\log P$ are not same, the regression coefficients of $R_{\mathrm{M}}{ }^{0}-\log P$ and $m-\log P$ relationships for the examined cyanoacetamides had different values (0.678-0.986). Bearing in mind all of the above, it was assumed that the examined relationships can be improved by introducing additional molecular descriptors. ${ }^{61,62}$

Using the online program Molinspiration, selected descriptors were determined, which fulfilled the modified rule of Lipinski: total polar surface molecules (TPSA), molecular mass (MW), molecular volume (V), number of hydrogen bond acceptors ( $\mathrm{nON})$, and the number of hydrogen bond donors (nONHN). In Table 7 values of Lipinski's molecular descriptors and TPSA and $\mathrm{V}$ are given.

Table 7. Computational calculated descriptors of cyanoacetamides that fit into modificated Lipinski's rule of five.

\begin{tabular}{|c|c|c|c|c|c|}
\hline substituent & MW & V & TPSA & nON & nOHNH \\
\hline $\mathrm{H}$ & 160.176 & 149.091 & 52.890 & 3 & 1 \\
\hline $\mathrm{CH}_{3}$ & 174.203 & 165.652 & 52.890 & 3 & 1 \\
\hline $\mathrm{I}$ & 286.072 & 173.081 & 52.890 & 3 & 1 \\
\hline $\mathrm{Br}$ & 239.072 & 166.976 & 52.890 & 3 & 1 \\
\hline $\mathrm{NO}_{2}$ & 205.173 & 172.425 & 98.714 & 6 & 1 \\
\hline $\mathrm{OH}^{2}$ & 176.175 & 157.109 & 73.118 & 4 & 2 \\
\hline $\mathrm{COOH}$ & 204.185 & 176.092 & 90.189 & 5 & 2 \\
\hline $\mathrm{COCH}_{3}$ & 202.213 & 184.635 & 69.961 & 4 & 1 \\
\hline $\mathrm{C}_{2} \mathrm{H}_{5}$ & 188.230 & 182.454 & 52.890 & 3 & 1 \\
\hline
\end{tabular}

Based on the data presented in Table 5 and Table 7 it could be concluded that the examined derivatives of cyanoacetamides are in accordance with the rule of Lipinski. Thus they have theoretically appropriate bioavailability in the body, and therefore good predisposition to exert its biological activity.

Equations of enhanced correlations established between chromatographic parameters, selected descriptors and standard measure of lipophilicity obtained by multiple regression analysis are presented in Table 8 . During the performing of a multiple linear regressions it was found that the impact of parameter $\mathrm{V}$ was not considered as relevant, because despite high $\mathrm{r}^{2}$ values, the $\mathrm{p}$ values were higher than 0.05 which indicates that the regression model is not good. 
Table 8. Chromatographic parameters, $R_{\mathrm{M}}{ }^{0}$ and $m$, of studied cyanoacetamides, as function of different $\log P$ values and selected descriptors.

\begin{tabular}{|c|c|c|c|}
\hline equation & $\mathbf{r}^{2}$ & $\mathbf{F}$ & $\mathbf{p}$ \\
\hline \multicolumn{4}{|l|}{$i$-propanol* } \\
\hline$R_{\mathrm{M}}{ }^{0}=1.813 \mathrm{AClog} P+0.048 \mathrm{TPSA}-0.003 \mathrm{MW}-0.421 \mathrm{nON}-0.517 \mathrm{nOHNH}-2.521$ & 0.997 & 122.738 & 0.008 \\
\hline$R_{\mathrm{M}}{ }^{0}=1.457 \mathrm{AB} \log P+0.086 \mathrm{TPSA}-0.006 \mathrm{MW}-1.148 \mathrm{nON}+0.121 \mathrm{nOHNH}-0.788$ & 0.989 & 35.202 & 0.028 \\
\hline$R_{\mathrm{M}}{ }^{0}=1.242 \mathrm{milog} P+0.028 \mathrm{TPSA}-1.949 \cdot 10^{-4} \mathrm{MW}-0.217 \mathrm{nON}-0.307 \mathrm{nOHNH}-0.528$ & 0.992 & 53.221 & 0.018 \\
\hline$R_{\mathrm{M}}{ }^{0}=1.071$ kowwin $+0.258 \mathrm{TPSA}+6.996 \cdot 10^{-4} \mathrm{MW}-3.947 \mathrm{nON}-0.935 \mathrm{nOHNH}-1.764$ & 0.991 & 46.486 & 0.021 \\
\hline$R_{\mathrm{M}}{ }^{0}=1.215 \mathrm{X} \log P_{3}+0.092 \mathrm{TPSA}-0.004 \mathrm{MW}-1.344 \mathrm{nON}-0.206 \mathrm{nOHNH}-1.158$ & 0.993 & 56.100 & 0.018 \\
\hline$m=-3.489 \mathrm{AClog} P-0.385 \mathrm{TPSA}+0.008 \mathrm{MW}+5.257 \mathrm{nON}+1.631 \mathrm{nOHNH}+5.056$ & 0.994 & 62.092 & 0.016 \\
\hline$m=-1.981 \mathrm{Alog} P-0.337 \mathrm{TPSA}-0.008 \mathrm{MW}+4.822 \mathrm{nON}+1.812 \mathrm{nOHNH}+2.628$ & 0.994 & 69.167 & 0.014 \\
\hline$m=-2.803 \mathrm{AB} \log P-0.456 \mathrm{TPSA}+0.014 \mathrm{MW}+6.651 \mathrm{nON}-0.402 \mathrm{nOHNH}+1.719$ & 0.980 & 19.263 & 0.050 \\
\hline$m=-2.335 \mathrm{X} \log P_{3}-0.467 \mathrm{TPSA}+0.011 \mathrm{MW}+7.014 \mathrm{nON}+1.029 \mathrm{nOHNH}+0.414$ & 0.986 & 28.375 & 0.034 \\
\hline \multicolumn{4}{|l|}{ dioxane** } \\
\hline$R_{\mathrm{M}}^{0}=0.394 \mathrm{AClog} P-0.152 \mathrm{TPSA}+0.003 \mathrm{MW}+2.329 \mathrm{nON}+0.181 \mathrm{nOHNH}+0.593$ & 0.997 & 128.893 & 0.008 \\
\hline$R_{\mathrm{M}}{ }^{0}=0.154 \mathrm{Alog} P-0.182 \mathrm{TPSA}+0.005 \mathrm{MW}+2.737 \mathrm{nON}+0.238 \mathrm{nOHNH}+1.134$ & 0.994 & 73.090 & 0.014 \\
\hline$R_{\mathrm{M}}{ }^{0}=0.084 \mathrm{AB} \log P-0.211 \mathrm{TPSA}+0.004 \mathrm{MW}+3.153 \mathrm{nON}+0.380 \mathrm{nOHNH}+1.535$ & 0.993 & 55.916 & 0.018 \\
\hline$R_{\mathrm{M}}{ }^{0}=0.110 \mathrm{milog} P-0.204 \mathrm{TPSA}+0.004 \mathrm{MW}+3.068 \mathrm{nON}+0.335 \mathrm{nOHNH}+1.456$ & 0.994 & 62.019 & 0.016 \\
\hline$R_{\mathrm{M}}^{0}=0.162 \mathrm{Mlog} P-0.203 \mathrm{TPSA}+0.004 \mathrm{MW}+3.056 \mathrm{nON}+0.369 \mathrm{nOHNH}+1.348$ & 0.993 & 57.574 & 0.017 \\
\hline$R_{\mathrm{M}}{ }^{0}=0.056$ kow win $-0.202 \mathrm{TPSA}+0.005 \mathrm{MW}+3.007 \mathrm{nON}+0.321 \mathrm{nOHNH}+1.483$ & 0.992 & 53.431 & 0.018 \\
\hline$m=0.185$ kowwin $+0.157 \mathrm{TPSA}-0.008 \mathrm{MW}-2.281 \mathrm{nON}-0.105 \mathrm{nOHNH}-2.810$ & 0.998 & 239.524 & 0.004 \\
\hline$m=0.231 \mathrm{X} \log P_{3}+0.136 \mathrm{TPSA}-0.009 \mathrm{MW}-1.948 \mathrm{nON}+0.008 \mathrm{nOHNH}-2.780$ & 0.998 & 282.227 & 0.004 \\
\hline
\end{tabular}

*compound with - $\mathrm{COOH}$ group is excluded from correlation.

**compound with $-\mathrm{H}$ group is excluded from correlation.

Results from Table 8 indicate that the introduction of new descriptors, provides more precisely definition of studied relationships $\left(r^{2}>0.984\right)$. Comparing two used modifiers it could be seen that higher value of regression coefficient are obtained in the case of dioxane. Also it is obvious that descriptor nON also has a major influence on establishing dependencies in both solvents. It is interesting because this descriptor characterizes the ability of the compound to participate in accepting hydrogen bonds. Thus it is confirmed that the chromatographic parameters represent the overall impact of the interactions that substance can achieve with mobile and stationary phase.

Determination of the pharmacokinetic predictors of $N$-(4-phenylmonosubstituted)-2-cyanoacetamides

For predicting biological activity of the newly synthesized compounds, in addition to the lipophilicity, it is necessary to know their pharmacokinetic characteristics. ${ }^{63}$

Taking this into account some important pharmacokinetic predictors of derivatives of $\mathrm{N}$-(4-substituted phenyl)-2-cyanoacetamide were calculated using the software package Simulation Plus (Table 9). In this way were determined $P_{\text {eff }}, R P B, U n b n d, V d$ and $\log B B B$ of studied derivatives.
Table 9. Pharmacokinetic predictors of the investigated cyanoacetamides.

\begin{tabular}{|l|l|l|l|l|l|}
\hline Substituent & $\begin{array}{c}\boldsymbol{P}_{\text {eff }} \\
(\mathbf{c m} / \mathbf{s})\end{array}$ & $\boldsymbol{R P B}$ & $\begin{array}{c}\text { Unbnd } \\
(\boldsymbol{\%})\end{array}$ & $\begin{array}{c}\boldsymbol{V} \boldsymbol{d} \\
(\mathbf{l} / \mathbf{k g})\end{array}$ & $\log \boldsymbol{B} \boldsymbol{B} \boldsymbol{B}$ \\
\hline $\mathrm{H}$ & 2.217 & 0.646 & 12.949 & 0.270 & -0.885 \\
\hline $\mathrm{CH}_{3}$ & 2.632 & 0.622 & 10.595 & 0.279 & -0.977 \\
\hline $\mathrm{I}$ & 3.479 & 0.611 & 12.489 & 0.239 & -0.890 \\
\hline $\mathrm{Br}$ & 3.246 & 0.616 & 8.835 & 0.238 & -0.906 \\
\hline $\mathrm{NO}_{2}$ & 2.352 & 0.633 & 20.672 & 0.273 & -0.889 \\
\hline $\mathrm{OH}$ & 1.252 & 0.632 & 11.752 & 0.263 & -0.932 \\
\hline $\mathrm{COOH}$ & 2.292 & 0.619 & 9.083 & 0.156 & -0.700 \\
\hline $\mathrm{COCH}_{3}$ & 2.289 & 0.619 & 8.829 & 0.292 & -0.759 \\
\hline $\mathrm{C}_{2} \mathrm{H}_{5}$ & 3.102 & 0.612 & 8.440 & 0.299 & -0.949 \\
\hline
\end{tabular}


From the data shown in Table 9 it is noticeable that among the studied cyanoacetamides, the most lipofilic derivative has the best predisposition for a strong absorption in the body, with -I as substituent since it possesses the highest $P_{\text {eff }}$ value, and the weakest has the polar compound with $-\mathrm{OH}$ as substituent. The values of predictor $R P B$ suggest that the examined derivatives don't have hematotoxic properties $(R P B<1)$. Also, predictor Unbnd indicates that the tested compounds bind to the plasma proteins in a higher degree $(8.829 \%-20.672 \%)$ causing lesser percentage of free fraction in plasma, which are responsible for their biological activity. The examined derivatives, do not have large values of $V d(<0.31 / \mathrm{kg})$ due to the presence of dominant polar amide group. Therefore these compounds will not be deposited in the adipose tissue and they can be eliminated from the organism quickly. Values of the distribution parameter through the blood brain barrier, $\log B B B$, show that there is no possibility of using the examined cyanoacetamides as neurologically active substances $(\log B B B \sim-1)$.
Correlation between pharmacokinetic predictors and chromatographic parameters, $R_{\mathrm{M}}{ }^{0}$ and $m$

Considering the fact that the lipophilicity has a significant impact on the behaviour of the compounds in a biological medium and thus on their pharmacokinetics, we assumed that a dependency can be established between the experimentally determined lipophilicity of the examined cyanoacetamide derivatives and their pharmacokinetics characteristics. ${ }^{64}$ Therefore chromatographic parameters $R_{\mathrm{M}}{ }^{0}$ and $m$, were correlated with different pharmacokinetic parameters $P_{\text {eff }}, R P B$, Unbnd, $V d$ and $\log B B B$ by classical linear regression method. However, the linear regression method did not give satisfactory results. With the idea that the obtained dependencies could be enhanced, Lipinski's descriptors were included, because as mentioned, they largely determine the bioavailability of a molecule in the body. ${ }^{65}$ Correlations were performed by applying multiple regression analysis (Table 10).

Table 10. Different pharmacokinetic predictors of studied cyanoacetamides, as function of chromatographic parameters, $R_{\mathrm{M}}{ }^{0}$ and $m$, and selected descriptors.

\begin{tabular}{|c|c|c|c|}
\hline equation & $\mathbf{r}^{2}$ & $\mathbf{F}$ & $\mathbf{p}$ \\
\hline \multicolumn{4}{|l|}{$i$-propanol } \\
\hline$P_{\text {eff }}=1.267 R_{\mathrm{M}}^{0}+0.320 \mathrm{TPSA}-0.016 \mathrm{~V}-4.968 \mathrm{nON}-1.627 \mathrm{nONHN}+3.348$ & 0.996 & 162.406 & $7.557 \cdot 10^{-4}$ \\
\hline$R P B=-0.011 R_{\mathrm{M}}{ }^{0}-0.004 \mathrm{TPSA}-2.199 \cdot 10^{-4} \mathrm{~V}+0.063 \mathrm{nON}+0.012 \mathrm{nONHN}+0.672$ & 0.995 & 72.085 & 0.014 \\
\hline$U n b=-3.564 R_{\mathrm{M}}{ }^{0}-3.429 \mathrm{TPSA}+0.033 \mathrm{MW}+55.561 \mathrm{nON}+12.177 \mathrm{nONHN}+11.319$ & 0.938 & 9.156 & 0.049 \\
\hline$V d=-0.103 R_{\mathrm{M}}^{0}-0.060 \mathrm{TPSA}+0.004 \mathrm{~V}+0.902 \mathrm{nON}+0.209 \mathrm{nONHN}-0.063$ & 0.989 & 54.783 & 0.004 \\
\hline $\log B B B=0.023 R_{\mathrm{M}}{ }^{0}+0.101 \mathrm{TPSA}+6.304 \cdot 10^{-4} \mathrm{MW}-1.526 \mathrm{nON}-0.460 \mathrm{nONHN}-1.425$ & 0.997 & 134.634 & 0.007 \\
\hline$P_{\text {eff }}=0.816 m+0.254 \mathrm{TPSA}-0.024 \mathrm{~V}-3.933 \mathrm{nON}-1.716 \mathrm{nONHN}+4.104$ & 0.990 & 56.636 & 0.004 \\
\hline$R P B=0.007 m-0.003$ TPSA $-1.523 \cdot 10^{-4} \mathrm{~V}+0.055 \mathrm{nON}+0.013 \mathrm{nONHN}+0.666$ & 0.990 & 38.705 & 0.025 \\
\hline$U n b=-2.159 m-3.044 \mathrm{TPSA}+0.033 \mathrm{MW}+49.646 \mathrm{nON}+11.286 \mathrm{nONHN}+12.224$ & 0.950 & 11.506 & 0.036 \\
\hline$V d=0.066 m-0.054 \mathrm{TPSA}+0.005 \mathrm{~V}+0.816 \mathrm{nON}+0.216 \mathrm{nONHN}-0.124$ & 0.977 & 25.113 & 0.012 \\
\hline $\log B B B=-0.014 m+0.099$ TPSA $+6.449 \cdot 10^{-4} \mathrm{MW}-1.488 \mathrm{nON}-0.454 \mathrm{nONHN}-1.435$ & 0.997 & 148.703 & 0.007 \\
\hline \multicolumn{4}{|l|}{ dioxane } \\
\hline$P_{\text {eff }}=1.119 R_{M^{0}}-0.032 \mathrm{TPSA}-1.076 \cdot 10^{-4} \mathrm{~V}+0.348 \mathrm{nON}-0.417 \mathrm{nONHN}+2.734$ & 0.994 & 61.990 & 0.016 \\
\hline$R P B=-0.019 R_{\mathrm{M}}{ }^{0}-0.004 \mathrm{TPSA}-5.589 \cdot 10^{-4} \mathrm{~V}+0.063 \mathrm{nON}+0.001 \mathrm{nONHN}+0.752$ & 0.963 & 15.720 & 0.023 \\
\hline$U n b=-7.308 R_{\mathrm{M}}{ }^{0}-4.544 \mathrm{TPSA}+0.055 \mathrm{MW}+72.421 \mathrm{nON}+15.286 \mathrm{nONHN}+15.432$ & 0.946 & 10.586 & 0.040 \\
\hline$V d=-0.092 R_{\mathrm{M}}^{0}-0.031 \mathrm{TPSA}+0.003 \mathrm{~V}+0.464 \mathrm{nON}+0.110 \mathrm{nONHN}-0.015$ & 0.986 & 27.881 & 0.035 \\
\hline $\log B B B=-0.151 R_{\mathrm{M}}^{0}+0.066 \mathrm{TPSA}+0.002 \mathrm{MW}-0.997 \mathrm{nON}-0.412 \mathrm{nONHN}-1.135$ & 0.975 & 23.766 & 0.013 \\
\hline$P_{\text {eff }}=-0.596 m-0.336 \mathrm{TPSA}+0.011 \mathrm{~V}+4.957 \mathrm{nON}+0.626 \mathrm{nONHN}+1.873$ & 0.974 & 14.949 & 0.064 \\
\hline$R P B=0.011 m+0.002 \mathrm{TPSA}-6.834 \cdot 10^{-4} \mathrm{~V}-0.030 \mathrm{nON}-0.018 \mathrm{nONHN}+0.755$ & 0.994 & 66.715 & 0.015 \\
\hline$U n b=3.209 m-3.356 \mathrm{TPSA}+0.034 \mathrm{MW}+54.396 \mathrm{nON}+12.790 \mathrm{nONHN}+13.311$ & 0.898 & 5.267 & 0.101 \\
\hline----- & --- & --- & --- \\
\hline $\log B B B=0.011 m+0.086 \mathrm{TPSA}+0.002 \mathrm{MW}-1.308 \mathrm{nON}-0.461 \mathrm{nONHN}-1.126$ & 0.997 & 183.393 & $6.304 \cdot 10^{-4}$ \\
\hline
\end{tabular}

From the results represented in Table 10 it can be seen that better relationships were obtained in $i$-propanol. It can be noted that descriptors nON and nOHNH have the greatest contribution in the majority of the established relationships. Also, it should be noted that among all pharmacokinetic predictors, $P_{\text {eff }}$ is best described by studied parameters. The reason is probably that the values of the selected pharmacokinetic predictors are primarily caused by the interactions that the compound could realize in the organism from the entry moment.

\section{CONCLUSIONS}

The newly synthesized derivatives of $N$-(4-phenylmonosubstituted)-2cyanoacetamides were studied in order to examine their potential bioactivity. Since the biological activity of the substance depends on its physical, chemical, and structural characteristics, predicting the behaviour of these compounds in some biological medium is based on studying their retention behaviour. Lipophilicity, as one of the most important molecular descriptors of the potential biological activity of the examined compounds, was determined experimentally by applying the RP-TLC and computationally by software. The obtained results indicate that the used modifier as well as the nature of substituent - $\mathrm{R}$ has influence on the retention behavior of the investigated cyanocetamides. The chromatographically obtained parameters, $R_{\mathrm{M}}{ }^{0}$ and $m$, were correlated with computationally calculated values of the standard measure of lipophilicity, $\log P$ applying linear regression analysis. The obtained correlations were enhanced with the Lipinski's descriptors by applying multiple regression analysis. Also, for the investigated compounds pharmacokinetic parameters Peff, RPB, Unbnd, $\mathrm{Vd}$ and $\log B B B$, as predictors of their bioactivity were calculated. As expected, the obtained values indicate the possible therapeutic applications of the studied derivatives. With the aim to establish a relationship between pharmacokinetic predictors on one side and chromatographically obtained criteria of lipophilicity and descriptors Lipinski on the other, the multiple regression method was performed. In this way satisfactory correlations were registered. Based on the obtained results it may be concluded that the chromatographic retention constant, $R_{\mathrm{M}}{ }^{0}$ and the chromatographic parameter, $m$, determined by RP-TLC method can be successfully applied as a measure of lipophilicity and a possible indicator of pharmacokinetics of $\mathrm{N}$-(4-phenylmonosubstituted)-2-cyanoacetamides, and with them, also of their biological activity. 


\section{ACKNOWLEDGEMENTS}

The presented results are the part of the research project No. 172013 supported by the Ministry of Education, Science and Technological Development of the Republic of Serbia. The authors are grateful to the team of SimulationsPlus for deferral a free trial version.

\section{REFERENCES}

1. S.M. Paul, D.S. Mytelka, C.T. Dunwiddie, C.C. Persinger, B.H. Munos, S.R. Lindborg, A.L. Schacht, Nat. Rev. Drug Discovery, 9, 203, (2010).

2. L. De Petrocellis, D. Melck, T. Bisogno, V. Di Marzo, Chem. Phys. Lipids, 108, 191, (2000).

3. F. Soto-Morales, J.S. Gómez-Jeria, J. Chil. Chem. Soc. 52, 1214, (2007).

4. E. Petrlíková, K. Waisser, K. Palát Jr., J. Kuneš, J. Kaustová, Chem. Pap. 65, 52, (2011).

5. P.S. Banerjee, P.K. Sharma, Med. Chem. Res. 21, 1491, (2012).

6. Y. Liu, G.Y. Zhang, Y. Li, Y.N. Zhang, S.Z. Zheng, Z.X. Zhou, S.J. An, Y.H. Jin, Heteroat. Chem. 24, 9, (2013).

7. D.J. Pacheco, J. Trilleras, J. Quiroga, J. Gutiérrez, L. Prent, T. Coavas, J.C. Marín, G. Delgado, J. Braz. Chem. Soc. 24, 1685, (2013).

8. F.F. Boyom, P.V.T. Fokou, L.R.Y Tchokouaha, T. Spangenberg, A.N. Mfopa, R.M.T. Kouipou, C.J. Mbouna, V.F.D. Donfack, P.H.A. Zollo, Antimicrob. Agents Chemother. 58, 5848, (2014).

9. N.S. Arutyunyan, L.A. Akopyan, R.L. Nazaryan, G.A. Gevorgyan, G.M. Stepanyan, R.V. Paronikyan, G.A. Panosyan, Pharm. Chem. J. 47, 490, (2013).

10. R. Wan, J.Q. Zhang, F. Han, P. Wang, P. Yu, Q. He, Nucleosides, Nucleotides Nucleic Acids, 30, 280, (2011).

11. M.L. Bernards, J.T. Simmons, C.J. Guza, C.R. Schulz, D. Penner, J.J. Kells, Weed Technol. 20, 458, (2006).

12. B. Reddy, S. Mohan, J.I. Talukdar, Int. J. ChemTech Res. 5, 2727, (2013)

13. D.Ü. Özkay, Y. Özkay, Ö.D. Can, Med. Chem. Res. 20, 152, (2011).

14. A.H. Tarikogullari, F.S. Kilic, K. Erol, V. Pabuccuoglu, Arzneim.Forsch./Drug Res. 60, 593, (2010).

15. S. Koppireddi, J.R. Komsani, S. Avula, S. Pombala, S. Vasamsetti, S. Kotamraju, R. Yadla, Eur. J. Med. Chem. 66, 305, (2013).

16. L. Morellato, M. Lefas-Le Gall, M. Langlois, D.H. Caignard, P. Renard, P. Delagrange, M. Mathé-Allainmat, Bioorg. Med. Chem. Lett. 23, 430, (2013).

17. H. Rajak, M.D. Kharya, P. Mishra, Arch. Pharm. 341, 247, (2008).

18. G. Veinberg, M. Vorona, L. Zvejniece, R. Vilskersts, E. Vavers, E. Liepinsh, H. Kazoka, S. Belyakov, A. Mishnev, J. Kuznecovs, S. Vikainis, N. Orlova, A. Lebedev, Y. Ponomaryov, M. Dambrova, Bioorg. Med. Chem. 21, 2764, (2013).

19. L. Yurttaş, Z.A. Kaplancikli, Y.J. Özkay, Enzyme Inhib. Med. Chem. 28, $1040,(2013)$

20. O. Akgül, A.H. Tarikoğullari, F.A. Köse, P.B. Kirmizibayrak, M.V. Pabuççuoğlu, Turk. J. Chem. 37, 204, (2013).

21. M. Duran, S. Demirayak, Med. Chem. Res. 22, 4110, (2013).

22. P. Zhan, W. Chen, Z. Li, X. Li, X. Chen, Y. Tian, C. Pannecouque, E.D. Clercq, X. Liu, Bioorg. Med. Chem. 20, 6795, (2012).

23. J.S. Gómez-Jeria, F. Soto-Morales, J. Rivas, A.J. Sotomayor, Chil. Chem. Soc. 53, 1393, (2008).

24. T. Baczek, R. Kaliszan, Proteomics, 9, 835, (2007).

25. M. Karelson, V.S. Lobanov, A.R. Katritzky, Chem. Rev. 96, 1027, (1996).

26. Z. Garkani-Nejad, F. Salehfard, J. Chil. Chem. Soc. 58, 2226, (2013).

27. E. Rutkowska, K. Pająk, K. Jóźwiak, Acta Pol. Pharm. 70, 3, (2013).

28. L. Prokai, N.M. Rivera-Portalatin, K. Prokai-Tatrai, Int. J. Mol. Sci. 14, 1443, (2013)

29. J. Stasiak, M. Koba, T. Baczek, Lett. Drug Des. Discovery, 11, 1017, (2014)

30. E.H. Kerns, L. Di, Drug Discov. Today, 8, 316, (2003).

31. T. Fujita, J. Iwasa, C. Hansch, J. Am. Chem. Soc. 86, 5175, (1964).

32. A. Leo, C. Hansch, D. Elkins, Chem. Rev. 71, 525, (1971)

33. S. Gocan, S. Cobzac, N. Grinberg, J. Liq. Chromatogr. Relat. Technol. 30, $1669,(2007)$.

34. D. Łazewska, P. Maludziński, E. Szymańska, K. Kieć-Kononiwicz, Biomed. Chromatogr. 21, 291, (2007).

35. A. Hawrył, E. Kumierz, P. Pisarczyk, M. Wujec, M. Waksmundzka-Hajnos, Acta Chromatogr. 24, 271, (2012).

36. G. Vastag, S. Apostolov, N. Perišić-Janjić, B. Matijević, Anal. Chim. Acta 767, 44, (2013)

37. G.Gy. Vastag, S.Lj. Apostolov, B.M. Matijević, A.D. Marinković, J. Braz. Chem. Soc. 25, 1948, (2014)

38. N. Perisic-Janjic, R. Kaliszan, N. Milosevic, G. Uscumlic, N. Banjac, J. Pharm. Biomed. Anal. 72, 65, (2013).
39. C.A. Lipinski, F. Lombardo, B.W. Dominy, P.J. Feeney, Adv. Drug Delivery Rev. 23, 3, (1997).

40. T. Hetal, P. Bindesh, T. Sneha, Int. J. Pharm. Sci. Rev. Res. 4, 203, (2010).

41. W.K. Sietsema, Int. J. Clin. Pharmacol., Ther. Toxicol. 27, 179, (1989).

42. Y.H. Zhao, J. Le, M.H. Abraham, A. Hersey, P.J. Eddershaw, C.N. Luscombe, D. Boutina, G. Beck, B. Sherborne, I. Cooper, J.A. Platts, J. Pharm. Sci. 90, 749, (2001).

43. H.J. Lennernäs, Pharm. Sci. 87, 403, (1998).

44. T.J. Hou, W. Zhang, K. Xia, X.B. Qiao, X.J. Xu, J. Chem. Inf. Model. 44, $1585,(2004)$.

45. P. Paixão, L.F. Gouveia, J.A.G. Morais, Eur. J. Pharm. Sci. 36, 544, (2009).

46. R.T. Scheife, Ann. Pharmacother. 23, 27, (1989).

47. L.Z. Benet, D.L. Kroetz, L.B. Sheiner in The pharmacological basis of therapeutics Pharmacokinetics. The dynamics of drug absorption distribution and elimination Goodman G.A., Gilman eds. McGraw-Hill, New York, 1996; pp. 3-27.

48. M. Hacker, K. Bachmann, W. Messer Pharmacology: Principles and Practice. Academic Press, Burlington, 2009.

49. P.L. Toutain, A. Bousquet-Mélou, J. Vet. Pharmacol. Ther. 27, 441, (2004).

50. M. Iyer, R. Mishra, Y. Han, A.J. Hopfinger, Pharm. Res. 19, 1611, (2002).

51. A.D. Marinković, D. Brkić, J.S. Martinović, D.Ž. Mijin, M. Milčić, S.D. Petrović, Chem. Ind. Chem. Eng. Q. 19, 67, (2013).

52. http://www.vcclab.org Accessed May 2011.

53. http://www.molinspiration.com Accessed June 2014.

54. http://www.simulations-plus.com September 2013.

55. G. Vastag, S. Apostolov, J. Nakomčić, B. Matijević, J. Liq. Chromatogr Relat. Technol. 37, 2529, (2014).

56. T.Lj. Djaković-Sekulić, N.U. Perišić-Janjić, S.D. Petrović, J. Planar Chromatogr.--Mod. TLC, 15, 274, (2002).

57. S.M. Petrović, E. Lončar, N.U. Perišić-Janjić, M.J. Lazarević, Planar Chromatogr.--Mod. TLC, 10, 26, (1997).

58. C. Sârbu, C. Onișor, M. Posa, S. Kevresan, K. Kuhajda, Talanta, 75, 651, (2008).

59. Gy. Vastag, S. Apostolov, B. Matijević, S. Petrović, J. Chromatogr. Sci. 53 $312,(2014)$.

60. G.L. Biagi, A.M. Barbaro, A. Sapone, M. Recanatini, J. Chromatogr. A, 662 , 341, (1994).

61. A. Kowalska, K. Pluta, J. Liq. Chromatogr. Relat. Technol. 35, 1686, (2012).

62. N.P. Milošević, S.Z. Stojanović, K. Penov-Gaši, N. Perišić-Janjić, R. Kaliszan, J. Pharm. Biomed. Anal. 88, 636, (2014).

63. S.S. Singh, Curr. Drug Metab. 7, 165, (2006).

64. S. Apostolov, G. Vastag, B. Matijevic, S. Petrovic, J. Liq. Chromatogr. Relat. Technol. 38, 1691, (2015).

65. N.P. Milošević, V.B. Dimova, N.U. Perišić-Janjić, Eur. J. Pharm. Sci. 49, $10,(2013)$ 